Provided for non-commercial research and education use. Not for reproduction, distribution or commercial use.

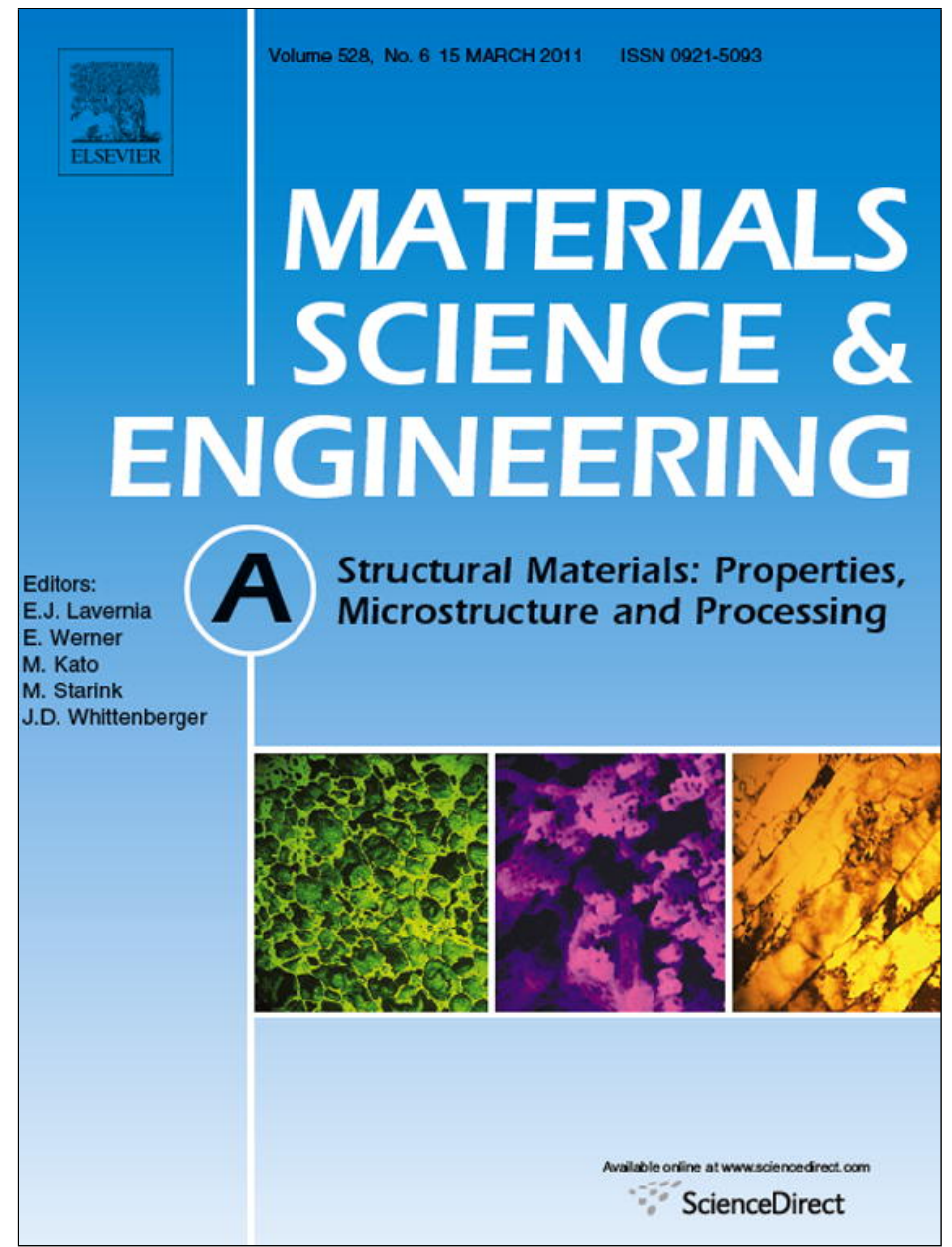

This article appeared in a journal published by Elsevier. The attached copy is furnished to the author for internal non-commercial research and education use, including for instruction at the authors institution and sharing with colleagues.

Other uses, including reproduction and distribution, or selling or licensing copies, or posting to personal, institutional or third party websites are prohibited.

In most cases authors are permitted to post their version of the article (e.g. in Word or Tex form) to their personal website or institutional repository. Authors requiring further information regarding Elsevier's archiving and manuscript policies are encouraged to visit:

http://www.elsevier.com/copyright 


\title{
Cold cracking in DC-cast high strength aluminum alloy ingots: An intrinsic problem intensified by casting process parameters
}

\author{
M. Lalpoor ${ }^{\mathrm{a}, *}$, D.G. Eskin ${ }^{\mathrm{a}, \mathrm{b}}$, D. Ruvalcaba ${ }^{\mathrm{c}}$, H.G. Fjær ${ }^{\mathrm{d}}$, A. Ten Cate ${ }^{\mathrm{c}}$, N. Ontijt ${ }^{\mathrm{c}}$, L. Katgerman $^{\mathrm{b}}$ \\ a Materials Innovation Institute, Mekelweg 2, 2628 CD Delft, The Netherlands \\ ${ }^{\mathrm{b}}$ Delft University of Technology, Department of Materials Science and Engineering, Mekelweg 2, 2628 CD Delft, The Netherlands \\ c Tata Steel Europe, 1970 CA IJmuiden, The Netherlands \\ ${ }^{\mathrm{d}}$ Institute for Energy Technology (IFE), P.O. Box 40, NO-2027 Kjeller, Norway
}

\section{A R T I C L E I N F O}

\section{Article history:}

Received 18 October 2010

Received in revised form

10 December 2010

Accepted 10 December 2010

Available online 17 December 2010

\section{Keywords:}

Aluminum alloys

DC-casting

Cold cracking

Thermomechanical simulations

Fracture

\begin{abstract}
A B S T R A C T
For almost half a century the catastrophic failure of direct chill (DC) cast high strength aluminum alloys has been challenging the production of sound ingots. To overcome this problem, a criterion is required that can assist the researchers in predicting the critical conditions which facilitate the catastrophic failure of the ingots. This could be achieved at first glance by application of computer simulations to assess the level and distribution of residual thermal stresses. However, the simulation results are only able to show the critical locations and conditions where and when high stresses may appear in the ingots. The prediction of critical void/crack size requires simultaneous application of fracture mechanics. In this paper, we present the thermo-mechanical simulation results that indicate the critical crack size distribution in several DCcast billets cast at various casting conditions. The simulation results were validated upon experimental DC-casting trials and revealed that the existence of voids/cracks with a considerable size is required for cold cracking to occur.
\end{abstract}

(C) 2010 Elsevier B.V. All rights reserved.

\section{Introduction}

Direct chill (DC) casting is the first step in the production of high strength aluminum alloys [1]. In spite of its robust nature and relative simplicity it can induce some voids and defects in the ingots. High cooling rates and non-equilibrium solidification conditions of the DC-casting result in the formation of nonequilibrium eutectics and intermetallics, which mainly precipitate on the grain boundaries and interdendritic spaces during final stages of solidification [2,3]. The formation of such phases coincides with the appearance of thermal stresses when the dendritic grains start to form a coherent network [4]. Due to their low melting point, the non-equilibrium eutectics provide potential nucleation sites and propagation paths for hot cracking (cracking above the solidus) while they are still in the liquid state. Below solidus, they provide a continuous network of brittle intermetallics on the interdendritic/intergranular spaces and make the material prone to intergranular brittle fracture [5-7]. The fracture of the intermetallics under triaxial loading conditions in the center of the billet may provide cracks of critical size which may facilitate the cold cracking [8].

\footnotetext{
* Corresponding author. Tel.: +31 152788700; fax: +31 152786730 .

E-mail address: mlalpoor@gmail.com (M. Lalpoor).
}

Regardless of the micro-scale cracking mechanism, voids/cracks of critical size should be present in the structure, at the tip of which the stresses are intensified to some critical levels. The critical crack/void size can be calculated by application of fracture mechanics and thermo-mechanical simulation of the residual thermal stresses developed in the billet during the casting process $[9,10]$. Thermo-mechanical simulation is a powerful computational tool that assists the researchers in better understanding the development of residual thermal stresses during the DC-casting process [11]. However, in order to calculate the critical crack/void size that results in catastrophic failure, the application of fracture mechanics is required. According to Rankine's theory, which is more applicable to brittle materials than other theories, the failure occurs when either the maximum principal stress reaches the uniaxial tensile strength or the minimum principal stress reaches the uniaxial compressive strength $[12,13]$. Experimental DC-casting trials have shown that DC-cast ingots suffer from failure under high tensile stress conditions rather than compressive ones $[7,14]$. Thus, the knowledge of the maximum principal stress along with the plane strain fracture toughness of the alloy in the genuine as-cast condition is necessary for any critical crack/void size assessment.

The brittleness of the material in the genuine as-cast condition is indeed the result of the special microstructure, but the level of thermal stresses developed during the casting is brought about by the poor thermo-physical properties of the material. A wider 
solidification temperature range, a lower thermal conductivity, and a relatively higher coefficient of thermal expansion compared to other aluminum alloys [15] led to high temperature gradients and consequently high thermal stresses in $7 x x x$ series aluminum ingots [16]. Therefore, high-strength aluminum alloys are intrinsically prone to cold cracking due to the poor thermo-physical properties and the special microstructure in the genuine as-cast condition. Under such conditions, any external parameter which can affect the temperature distribution and consequently the corresponding thermal stresses in the billet might make it even more prone to cracking. The casting process parameters such as casting speed and billet size can affect the stress level, distribution and orientation, which in turn influence the failure probability of the billets (ingots) [17].

In order to assist the industry in better understanding the cold cracking phenomenon and to provide a predictive tool, a proper criterion has to be established. Since the first reports on cold cracking in 1940s and 1950s [18,19], some works have been performed mainly as case studies to prevent cold cracking $[20,21]$. First criteria on cold cracking were based on the analysis of numerous industrial trials and included the requirement for the minimum ductility of the as-cast material or a relationship between casting speed and ingot size [22]. Recently, some researchers applied the fracture mechanics to thermo-mechanical simulations with the aim to predict the critical crack size $[9,10]$. However, their results have never been validated upon experimental DC-casting trials. In this research work, we present the simulation results for the AA7050 alloy cast under various conditions. The effect of the casting speed and billet diameter on the failure probability of the billets was studied using the contour maps of the critical crack size. The predictions of the criterion for a typical $7 x x x$ series aluminum alloy were validated upon pilot scale casting trials. The findings of this paper may be useful to aluminum industry in prediction and prevention of cold cracks.

\section{Computer simulation process}

ALSIM5 ${ }^{1}$ was used for the computation of temperature profile and stress/strain fields for round AA7050 billets under various casting conditions. A detailed description of the models involved can be found elsewhere [23-26]. The simulated geometry consisted of the hot top, mold, water jet, bottom block and the casting domain as shown in Fig. 1. 2D-rectangular elements were used that become finer on moving from the center towards the surface of the billet (Fig. 1). As the bottom block moves downwards during casting, new elements with a size of $0.75 \mathrm{~mm}$ are added to the geometry at the casting speed to simulate the continuous casting conditions. Meanwhile, the mold, hot top and molten metal retain their initial position. Simulations were run in 2D and due to axial symmetry, only half of the billet was considered. Time-dependent thermal boundary conditions are defined to account for filling time, air gap formation between the billet and the bottom block as well as at the billet surface, and for different heat extraction in different parts of the casting system [27]. The casting process parameters are shown in Table 1 for three various cases. Case 1 is a $200-\mathrm{mm}$ diameter billet cast at the speed $1 \mathrm{~mm} / \mathrm{s}$. In the second case, the casting speed is increased to $2 \mathrm{~mm} / \mathrm{s}$ while the billet diameter is unchanged. In the third case, the billet diameter is increased while the casting speed is the same as in Case 1. For Cases 2 and 3, water flow rates were increased accordingly to compensate for the higher heat input related to the greater mass of hot metal coming into the mold. The casting times were selected in such a way to make sure that the steady-state conditions are reached.

${ }^{1}$ ALSIM is a casting-simulation software developed by the Norwegian Institute for Energy Technology (IFE), Kjeller, Norway.

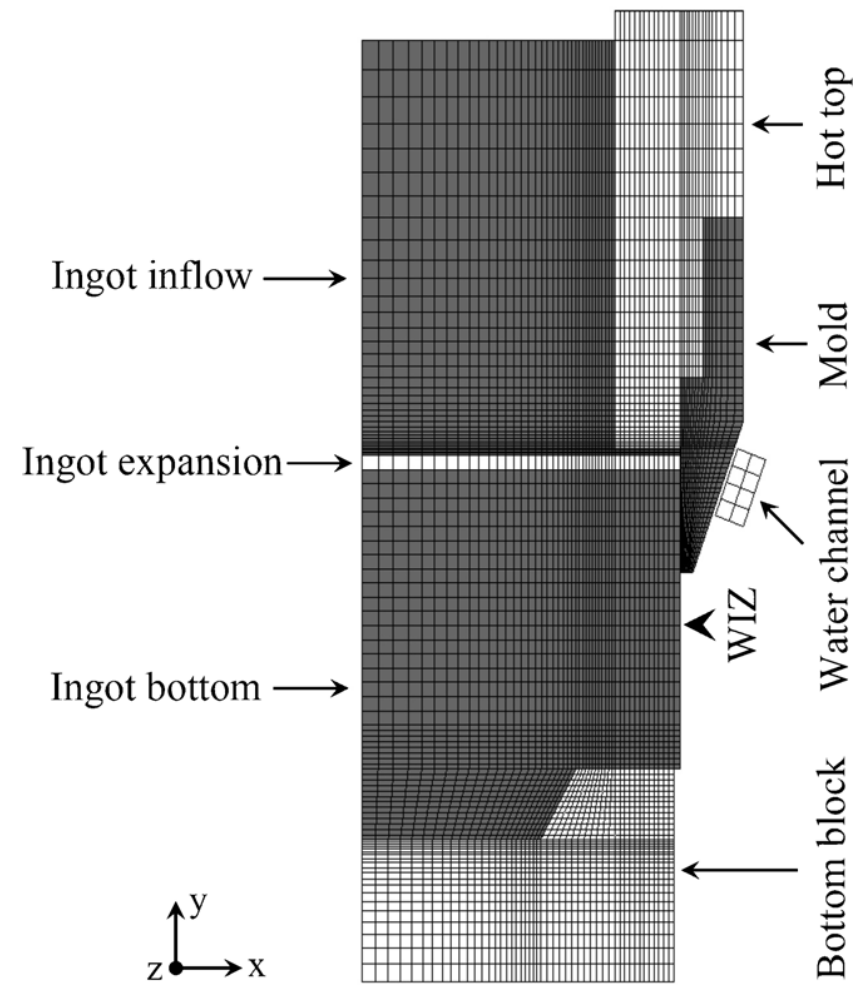

Fig. 1. Geometry of the DC-cast billet used for simulations showing the hot top mold, bottom block, and the casting aluminum part consisting of cast top, cas expansion and cast bottom. Approximate position of the Water Impingement Zone (WIZ) is also indicated on the billet surface.

Table 1

Description of the casting process parameters for the 7050 alloy.

\begin{tabular}{lrrr}
\hline Process parameter & Case 1 & Case 2 & Case 3 \\
\hline Ingot diameter $(\mathrm{mm})$ & 200 & 200 & 400 \\
Final length of the billet $(\mathrm{mm})$ & 380 & 530 & 900 \\
Casting speed $(\mathrm{mm} / \mathrm{s})$ & 1 & 2 & 1 \\
Melt temperature $\left({ }^{\circ} \mathrm{C}\right)$ & 680 & 680 & 680 \\
Water flow rate $(1 / \mathrm{min})$ & 80 & 200 & 400 \\
Water temperature $\left({ }^{\circ} \mathrm{C}\right)$ & 15 & 15 & 15 \\
\hline
\end{tabular}

Chemical composition of the tested alloy is listed in Table 2. Thermal as well as physical properties of the alloy were obtained from the thermodynamic database JMat-Pro (Sente Software Ltd., Surrey Technology Center, 40 Occam Road, GU2 7YG, United Kingdom) provided by Corus-Netherlands (IJmuiden) and are shown in Table 3. The liquidus and non-equilibrium solidus were determined through differential scanning calorimetry (DSC) tests for the grain refined alloy as 632 and $462{ }^{\circ} \mathrm{C}$, respectively. The fraction liquid in the solidification range between the liquidus and the non-equilibrium solidus was calculated by Scheil's equation (JMat-Pro) and results are shown in Table 4. In ALSIM5, the latent heat of solidification is included in the enthalpy and is released as enthalpy is reduced due to cooling [28]. Mechanical properties and constitutive parameters of the grain refined alloy were measured by present authors in the genuine as-cast condition (Table 5) and the details may be found elsewhere $[8,29]$. Mechan-

Table 2

Chemical composition of the 7050 alloy.

\begin{tabular}{llllllllll}
\hline \multicolumn{1}{l}{ Alloying elements (wt\%) } & \multicolumn{1}{l}{$l$} & & & & & \\
\hline $\mathrm{Zn}$ & $\mathrm{Mg}$ & $\mathrm{Cu}$ & $\mathrm{Zr}$ & $\mathrm{Cr}$ & $\mathrm{Mn}$ & $\mathrm{Ti}$ & $\mathrm{Fe}$ & $\mathrm{Si}$ & $\mathrm{Al}$ \\
\hline 6.3 & 2.42 & 2.49 & 0.098 & $<0.01$ & 0.04 & 0.03 & 0.07 & 0.04 & Balance
\end{tabular}


Table 3

Thermal properties of the 7050 alloy used for simulations (JMat-Pro).

\begin{tabular}{clll}
\hline Temp. $\left({ }^{\circ} \mathrm{C}\right)$ & Density $\left(\mathrm{kg} / \mathrm{m}^{3}\right)$ & Thermal conductivity $(\mathrm{W} / \mathrm{m} \mathrm{K})$ & Coefficient of thermal expansion $\left(10^{-5} / \mathrm{K}\right)$ \\
\hline 20 & 2825.8 & 149.4 & 2.29 \\
100 & 2811.0 & 156.0 & 2.45 \\
200 & 2790.1 & 162.7 & 2.67 \\
300 & 2767.8 & 168.2 & 2.88 \\
400 & 2744.1 & 173.0 & 3.10 \\
500 & 2699.8 & 160.9 & 3.45 \\
600 & 2629.9 & 124.5 & 4.03 \\
632 & 2515.0 & 80.8 & 4.88 \\
700 & 2491.6 & 83.2 & 5.11 \\
\hline
\end{tabular}

Latent heat of fusion $\left(\right.$ at $\left.461{ }^{\circ} \mathrm{C}\right)=376.14 \times 10^{3} \mathrm{~J} / \mathrm{kg}$.

Table 4

Fraction liquid gained from Scheil's equation for the 7050 alloy (JMat-Pro).

\begin{tabular}{llllllllllll} 
Temp. $\left({ }^{\circ} \mathrm{C}\right)$ & 632 & 631 & 630 & 625 & 620 & 610 & 600 & 580 & 540 & 500 & 460 \\
\hline$f_{1}$ & 1 & 0.97 & 0.94 & 0.78 & 0.65 & 0.49 & 0.38 & 0.27 & 0.16 & 0.12 & 0 \\
\hline
\end{tabular}

ical behavior of the material at high temperatures is different in different temperature ranges. Therefore, different models are used to describe this behavior and some characteristic temperatures define the boundaries between them. The extended Ludwik's equation [30] and ALSPEN equations [27] were used to simulate the viscoplastic behavior of the material below the onset temperature of strain hardening $\left(390^{\circ} \mathrm{C}\right)$ [27]. Between this temperature and the so-called merge-properties-temperature, low temperature strain hardening equations (Ludwik and ALSPEN) are merged with the mushy zone equations (a cohesion model) [31] and details on the models may be found elsewhere [32]. The merge-propertiestemperature is defined to be a few degrees below the solidus $\left(455^{\circ} \mathrm{C}\right)$. Between merge-properties-temperature and rigidity temperature (onset of thermal contraction in the mushy zone, $559^{\circ} \mathrm{C}$, which was measured experimentally by present authors using the solidification contraction setup [33]) the cohesion model [31] was used to simulate the thermo-mechanical behavior of the material in the mushy zone. As the rheological parameters of the 7050 alloy are not available in the literature, the rheological parameters of the $\mathrm{Al}-2 \mathrm{wt} \% \mathrm{Cu}$ were used instead [34].

As a good approximation, the grain refined material under discussion can be assumed to be homogeneous and isotropic, i.e. in macroscopic view there is no preferred crack orientation and cracks propagate normal to the maximum principal stress component [35]. Having the plane strain fracture toughness of the material and assuming the ingot as a semi-infinite medium, one can calculate by application of fracture mechanics the critical crack size that leads to catastrophic brittle fracture $[9,13]$. To achieve this goal, a new module is added to ALSIM5 which uses the plane strain fracture toughness $\left(K_{\mathrm{Ic}}\right)$ of the material in the as-cast condition [8] and the maximum principal stress $\left(\sigma_{11}\right)$ component acting at the corresponding location. To calculate the critical crack size (CCS), the penny shaped crack (PSC) (Fig. 2a) was chosen for the bulk of the billet and the vicinity of the surface. The critical crack size for brittle fracture corresponding to this geometry is calculated as follows

\section{Table 5}

Constitutive parameters and mechanical properties of the 7050 alloy. Poisson's ratio (JMat-Pro) is also shown. $K$ is the consistency of the alloy (stress at $\varepsilon=1$ and $\left.\varepsilon=1 \mathrm{~s}^{-1}\right), n$ is the strain hardening coefficient and $m$ is the strain rate sensitivity in the extended Ludwik's equation [29]. $E$ is Young's modulus.

\begin{tabular}{clllll}
\hline Temp. $\left({ }^{\circ} \mathrm{C}\right)$ & $K(\mathrm{MPa})$ & $n$ & $m$ & $E(\mathrm{GPa})$ & Poisson's ratio \\
\hline 20 & $774 \pm 32$ & $0.42 \pm 0.02$ & 0 & 67.9 & 0.338 \\
100 & $626 \pm 13$ & $0.38 \pm 0.01$ & 0 & 64.9 & 0.341 \\
200 & $392 \pm 11$ & $0.21 \pm 0.006$ & 0 & 61.2 & 0.346 \\
300 & $199 \pm 4.5$ & $0.11 \pm 0.007$ & $0.03 \pm 0.007$ & 57.4 & 0.352 \\
400 & $174 \pm 5$ & $0.09 \pm 0.01$ & $0.15 \pm 0.009$ & 53.6 & 0.358 \\
\hline
\end{tabular}

based on Griffith's analysis [36]:

$a_{c}=\frac{\pi}{4}\left(\frac{K_{\mathrm{Ic}}}{\sigma}\right)^{2}$.

At the surface of the billet, the surface breaking semi-circular (thumbnail) crack (Fig. 2b) is chosen, for which the critical crack size is related to the $K_{\mathrm{Ic}}$ and nominal stress is as follows [36]:

$a_{c}=\frac{\pi}{(2 \times 1.13)^{2}}\left(\frac{K_{\mathrm{Ic}}}{\sigma}\right)^{2}$.

\section{Simulation results for $\mathrm{AA7050}$ and discussion}

Fig. 3 shows the simulation results for the 200 -mm billet cast at $1 \mathrm{~mm} / \mathrm{s}$ after $380 \mathrm{~s}$ of casting when steady-state conditions are already obtained. As can be seen in Fig. 3a, after $380 \mathrm{~s}$ of casting the temperature in the lower part of the billet is already below $80^{\circ} \mathrm{C}$. For the detailed explanation of the stress tensor components in the billet and their time evolution, one may refer to the previous works of present authors $[8,16]$. It is however worth to recall that under steady-state casting conditions, stresses are mainly tensile in the center of the billet and with moving towards the surface they either diminish or turn to compressive. In the water impingement zone (WIZ; shown in Fig. 1), the circumferential stress appears to be highly tensile, which immediately turns to compressive as the billet leaves the impingement zone. One consequence of having a triaxial tensile stress state in the center of the billet may be observed in Fig. 3b, where the mean (hydrostatic) stress $\left(\sigma_{\mathrm{m}}\right)$ takes high values in the center of the billet ( $48 \mathrm{MPa}$ ). Similar situation is observed at the surface of the billet in the WIZ $\left(\sigma_{\mathrm{m}}=30 \mathrm{MPa}\right)$. This explains why $7 x x x$ series aluminum alloys are so prone to cracking at these two locations. The higher the tri-axial stresses, the higher would be the chance of plastic constraint at the tip of the voids and cracks, and consequently the higher the chance of brittle fracture [37]. Luckily, in round ingots (billets), the tensile circumferential stresses in the WIZ are replaced by the compressive ones as a result of the contraction of the center. In spite of this, at some locations of the billet, e.g. on top of the bottom block the micro-cracks induced by tensile stresses may reach the critical length and propagate [38-40]. An example of such cracks may be seen in Fig. 4. Although such cracks are more suspected to be hot cracks rather than cold cracks, the exact determination of their type is not that straight forward. This is mainly due to the fact that the eventual fractographic features of hot and cold cracks may resemble each other [6,41]. Moreover, the cold cracking may be a continuation of hot cracking which makes the distinction even more complicated [8].

Fig. $3 \mathrm{c}$ shows the contour map of the $\sigma_{11}$ in the billet cast under conditions of Case 1. As can be seen, the $\sigma_{11}$ gains its maximum values in the WIZ (100 MPa) as well as the center of the billet (71 MPa). This component of the principal stress tensor was applied to Eq. (1) along with the $K_{\mathrm{Ic}}$ values $\left(200^{\circ} \mathrm{C}: 8.3 \pm 0.2 \mathrm{MPa} \mathrm{m}^{1 / 2}, 100^{\circ} \mathrm{C}\right.$ : $8.6 \pm 0.2 \mathrm{MPa} \mathrm{m}^{1 / 2}$ and room temperature: $8.9 \pm 0.3 \mathrm{MPa} \mathrm{m}^{1 / 2}[8]$ ) in order to calculate the critical crack size. The results are shown 

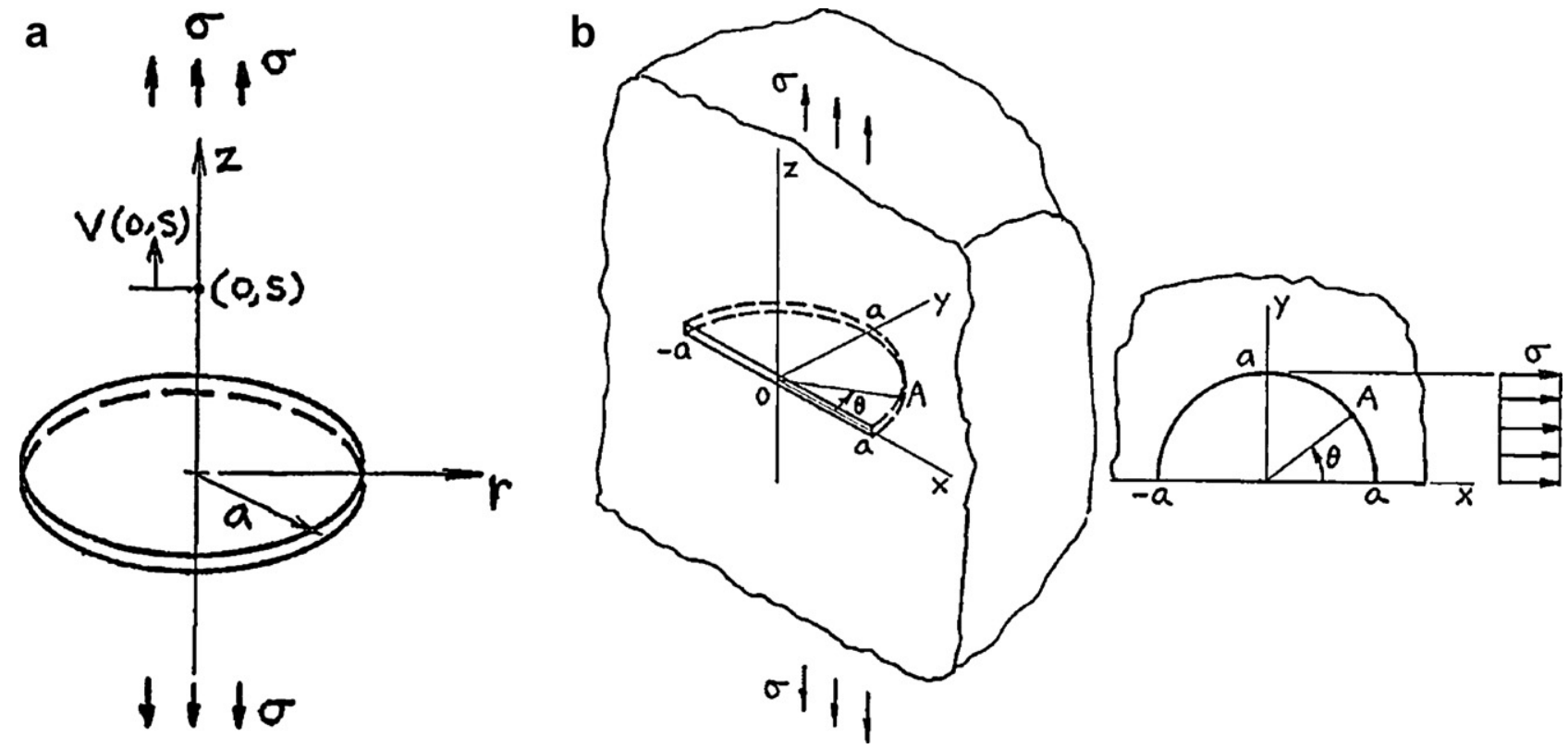

Fig. 2. Schematic view of the crack geometries used in this study: (a) a penny shaped crack. $V(0, s)$ is the displacement at $(0, s)$ when uniform pressure $\sigma$ is applied on crack surfaces, (b) a thumbnail crack in a semi-infinite body $(y \geq 0)(y=0$ : free surface) [36].

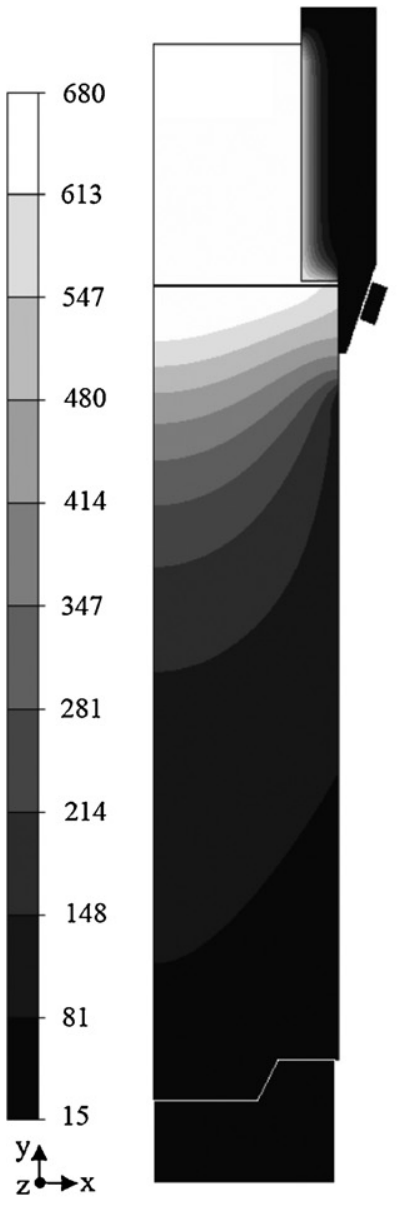

(a) Temperature $\left({ }^{\circ} \mathrm{C}\right)$

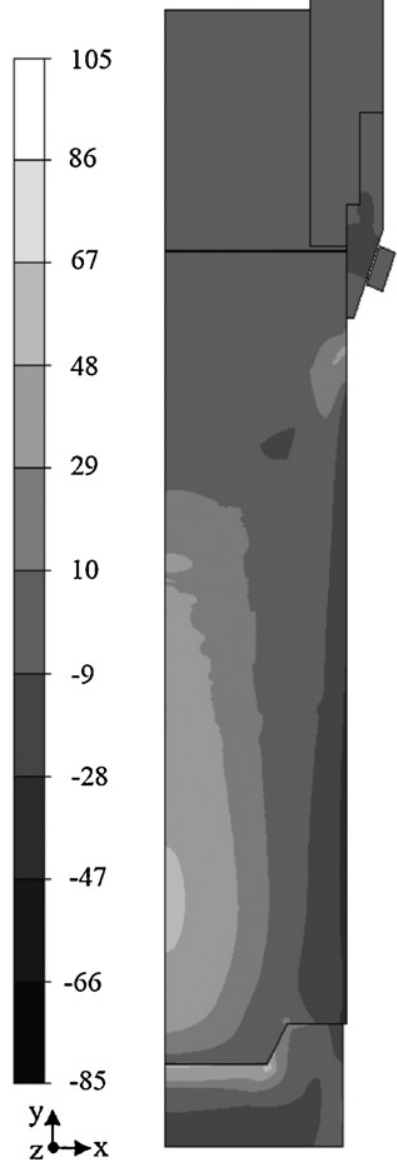

(b) $\sigma_{\mathrm{m}}(\mathrm{MPa})$

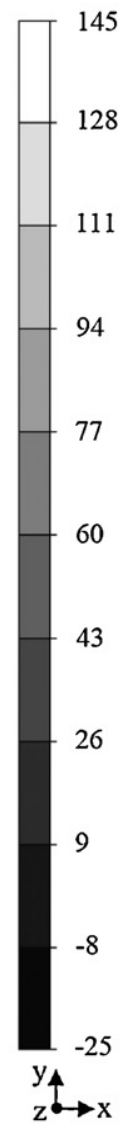

(c) $\sigma_{11}(\mathrm{MPa})$
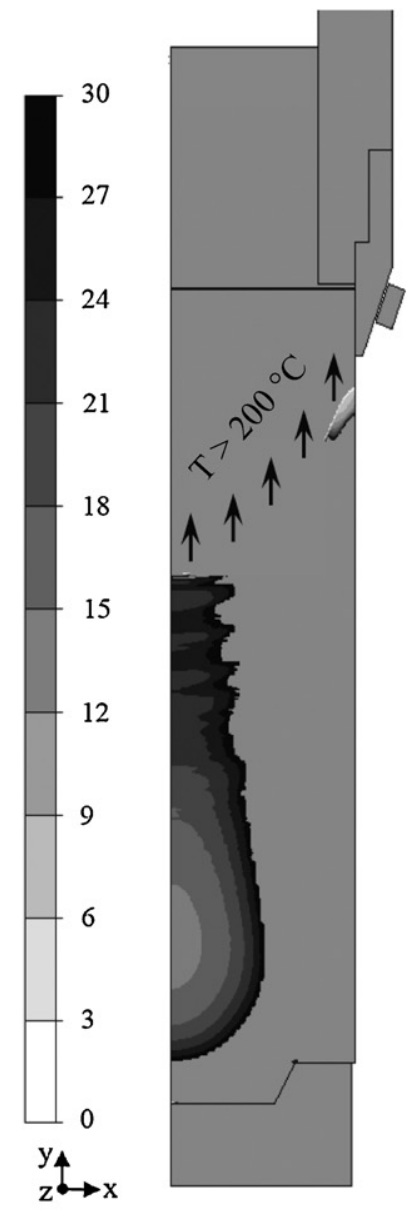

(d) $\operatorname{CCS}(\mathrm{mm})$

Fig. 3. Simulation results for the $200-\mathrm{mm}$ diameter billet cast at $1 \mathrm{~mm} / \mathrm{s}$ after $380 \mathrm{~s}$ of casting: (a) temperature profile, (b) mean (hydrostatic) stress, (c) maximum principal stress and (d) the critical crack size distribution; the arrows show the area with temperatures higher than $200^{\circ} \mathrm{C}$ 


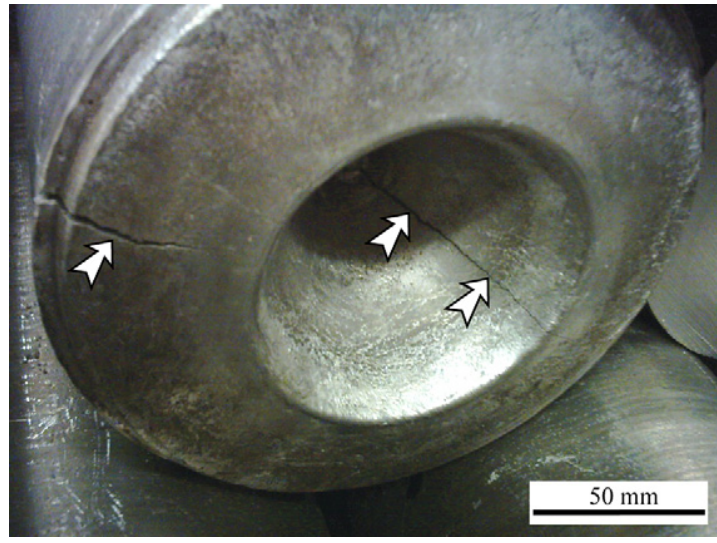

Fig. 4. A photo showing a 200-mm diameter 7475 DC-cast billet. The arrows show the surface cracks on the bottom of the billet.

in Fig. 3d. The smallest critical crack size appears in the WIZ in the vicinity of the surface, where cracks of 6-8 $\mathrm{mm}$ (corresponding temperatures: $180-200^{\circ} \mathrm{C}$ ) may trigger the failure. In the center of the billet this reads $10.7 \mathrm{~mm}$ (corresponding temperatures: $100-115^{\circ} \mathrm{C}$ ). The PSC would not be the right choice for the surface of the billet due to its geometry constraints. Therefore, for this specific location the surface breaking semi-circular (thumbnail) crack was chosen and the resulted critical crack size is $4.2 \mathrm{~mm}$. Our earlier experimental results [8] showed that above $200^{\circ} \mathrm{C}$, the plane strain conditions are not valid anymore and for measurement of the $K_{\mathrm{Ic}}$ at higher temperatures very large samples are required. As a result, the calculation of critical crack size was not possible above $200^{\circ} \mathrm{C}$ and the corresponding area is marked in Fig. $3 \mathrm{~d}$.

Fig. 5 shows similar contour maps as in Fig. 3 but for a billet cast under the conditions of Case 2, i.e. a $200-\mathrm{mm}$ billet cast at $2 \mathrm{~mm} / \mathrm{s}$. As can be seen in Fig. 5a, the higher casting speed has resulted in a deeper sump which in turn increases the temperature gradients especially in the axial direction of the billet $(-y)$. The increase in the temperature gradients leads to the increase of the thermal stress level in the billet in all directions [17,42]. A direct consequence of this is the increase of the mean stress level to $103 \mathrm{MPa}$ in the center of the billet and to $39 \mathrm{MPa}$ in the WIZ (Fig. 5b). Comparing the situation to Case 1 , one concludes that the mean stress is more than doubled in the center of the billet, which increases the plastic constraint and the probability of brittle fracture. Fig. $5 \mathrm{c}$ indicates the distribution of the $\sigma_{11}$ in the billet. Another consequence of the stress level elevation in the billet may be observed here, where the

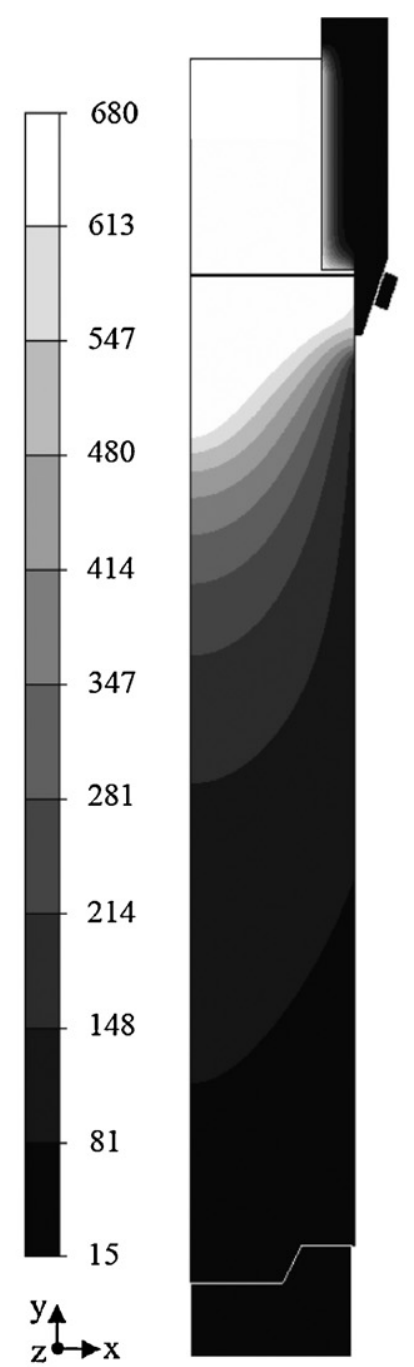

(a) Temperature $\left({ }^{\circ} \mathrm{C}\right)$
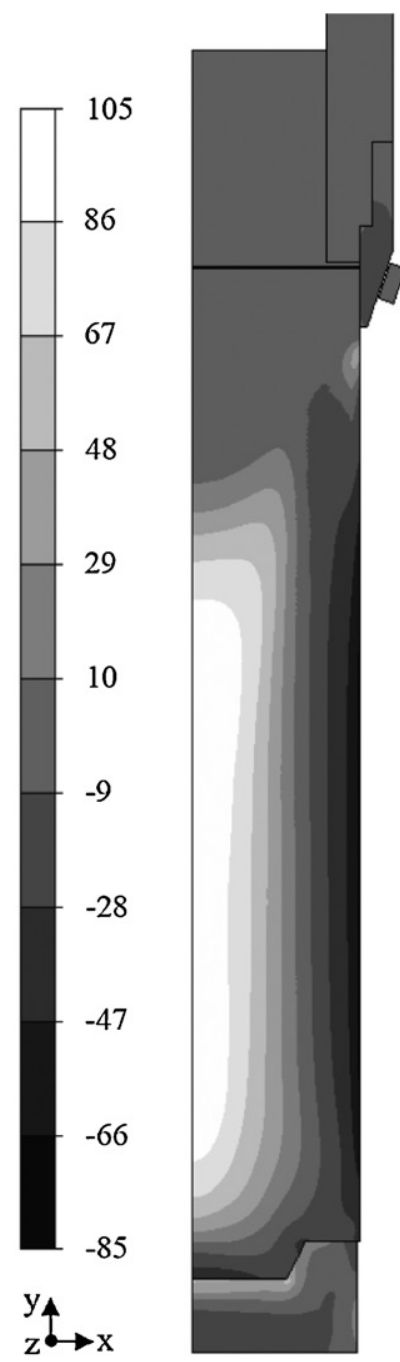

(b) $\sigma_{\mathrm{m}}(\mathrm{MPa})$
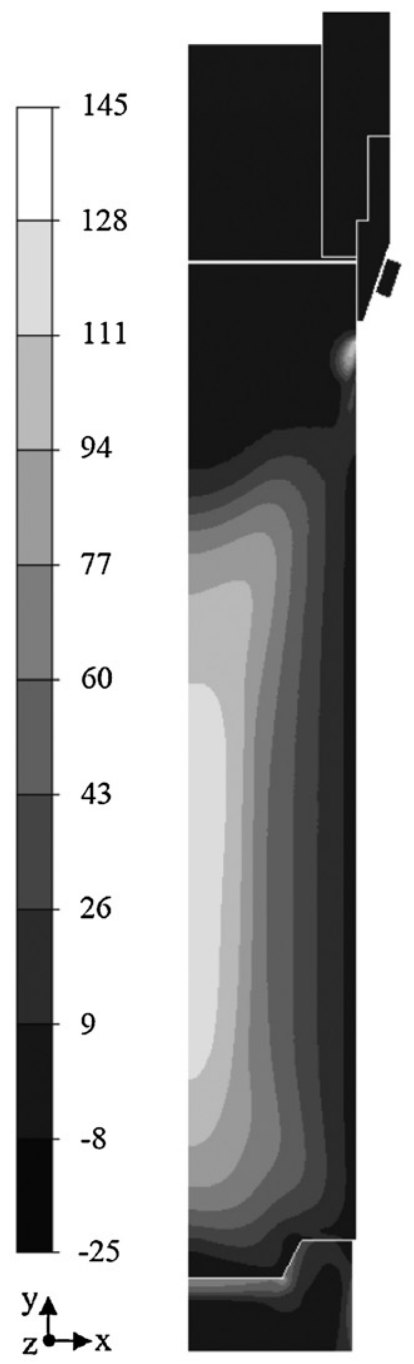

(c) $\sigma_{11}(\mathrm{MPa})$
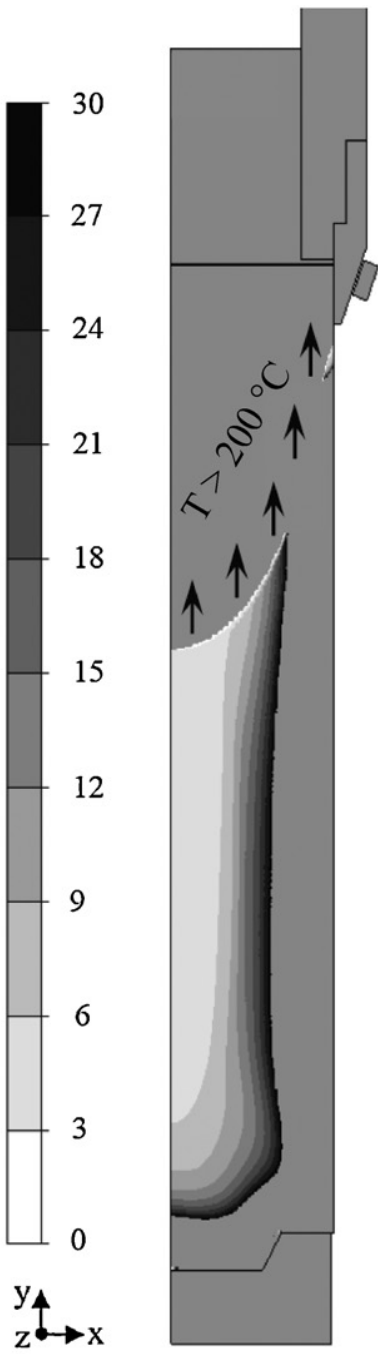

(d) $\operatorname{CCS}(\mathrm{mm})$

Fig. 5. Simulation results for the 200-mm diameter billet cast at $2 \mathrm{~mm} / \mathrm{s}$ after $310 \mathrm{~s}$ of casting: (a) Temperature profile, (b) mean (hydrostatic) stress, (c) maximum principal stress and (d) the critical crack size distribution; the arrows show the area with temperatures higher than $200^{\circ} \mathrm{C}$. 


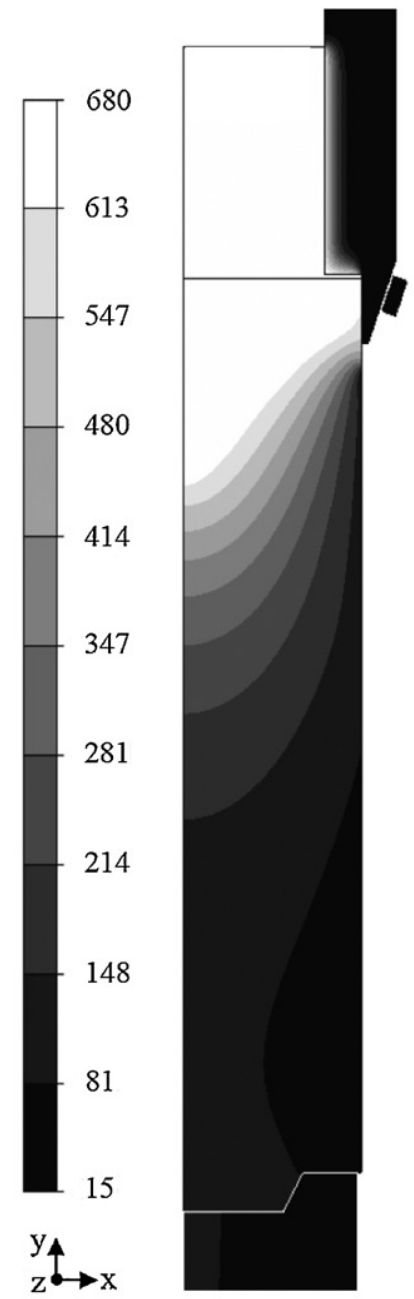

(a) Temperature $\left({ }^{\circ} \mathrm{C}\right)$

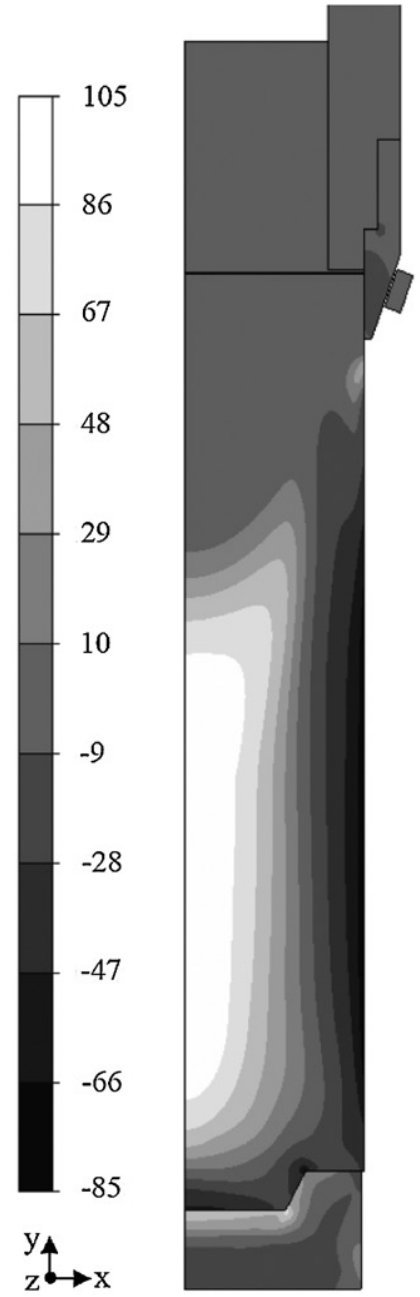

(b) $\sigma_{\mathrm{m}}(\mathrm{MPa})$
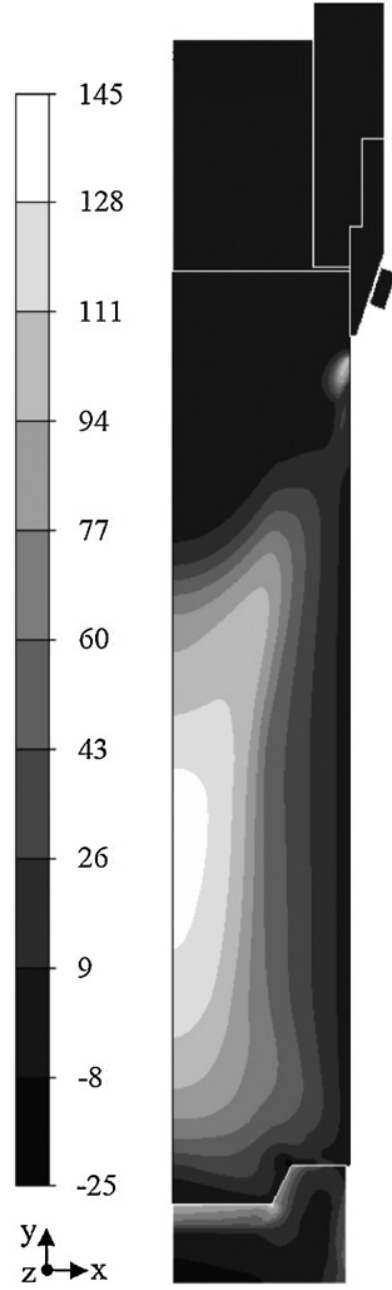

(c) $\sigma_{11}(\mathrm{MPa})$
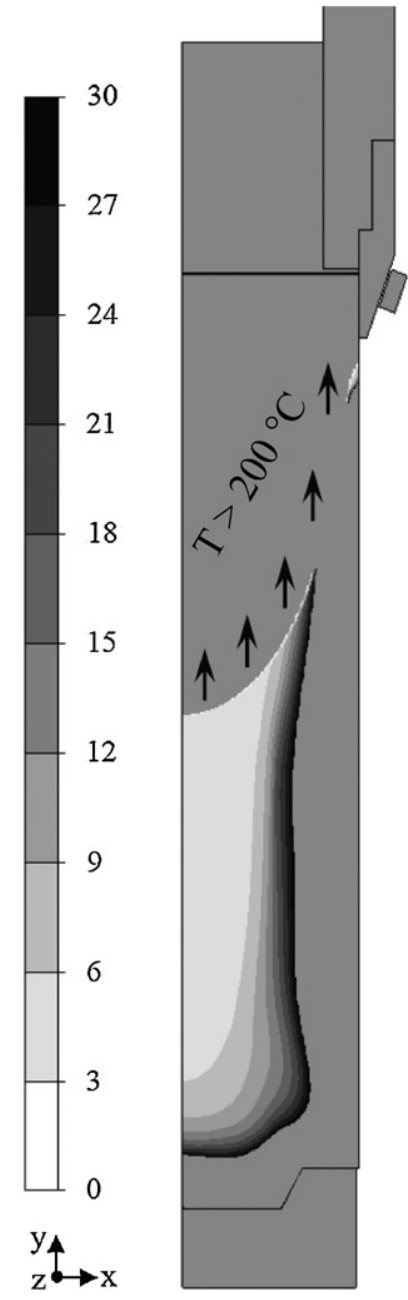

(d) $\operatorname{CCS}(\mathrm{mm})$

Fig. 6. Simulation results for the 400-mm diameter billet cast at $1 \mathrm{~mm} / \mathrm{s}$ after $900 \mathrm{~s}$ of casting: (a) Temperature profile, (b) mean (hydrostatic) stress, (c) maximum principal stress and (d) the critical crack size distribution; the arrows show the area with temperatures higher than $200^{\circ} \mathrm{C}$.

$\sigma_{11}$ has increased to $125 \mathrm{MPa}$ in the center and $105 \mathrm{MPa}$ in the WIZ at the surface. The contour map of the critical crack size (CCS) is shown in Fig. $5 \mathrm{~d}$, where the minimum CCS appears to be $3.5-5 \mathrm{~mm}$ in the center of the billet and 5-6 mm in the WIZ. The thumbnail crack size at the surface of the billet was calculated as $3.8 \mathrm{~mm}$. Compared to Case 1, the critical crack size has decreased dramatically in the center of the billet, but in the WIZ the changes are smaller. By comparing Fig. $5 c$ and d with Fig. $3 c$ and $d$ one learns that the area corresponding to the largest $\sigma_{11}$ and the minimum critical crack size has grown in the center of the billet, which indicates the higher failure probability in that area. In the WIZ however, the corresponding area has shrunk, which results directly from the higher casting speed and the fact that the billet spends shorter times in the impingement zone.

In order to study the effect of billet diameter on the state of residual thermal stresses and the failure probability, simulations were run under the conditions mentioned for Case 3 (Table 1). The results are shown in Fig. 6. Similar to increasing the casting speed, the increase in the billet diameter results in a deeper sump (Fig. 6a) mainly due to the longer thermal diffusion path to the surface $[17,42]$. This results in higher temperature gradients especially in the axial direction of the billet $(-y)$. According to Fig. $6 \mathrm{~b}$, the mean stress does not change noticeably compared to Case 2, i.e. $103 \mathrm{MPa}$ in the center and $36 \mathrm{MPa}$ in the WIZ. Unlike the mean stress, the maximum principal stress (Fig. 6c) increases even more in the center of the billet and reaches $135 \mathrm{MPa}$. In the WIZ it remains more or less the same as in Case 2, i.e. $105 \mathrm{MPa}$. The critical crack size in the center of the billet is in the range of 3-5 $\mathrm{mm}$ and 5-6 $\mathrm{mm}$ in the WIZ (Fig. 6d). The calculated thumbnail crack size at the surface of the billet is similar to Case 2, i.e. $3.8 \mathrm{~mm}$.

It is worth mentioning that at small billet diameters and low casting speeds (Case 1) the maximum principal stress in the center of the billet is oriented either in the radial or circumferential directions, while by either increasing the casting speed or billet diameter it turns towards the axial direction of the billet [17]. As a result the crack plane rotates will be discussed further in Section 4 .

\section{Validation of the simulation results upon casting a $7 x x x$ series aluminum alloy}

\subsection{Experimental procedure}

In order to check the validity of the cold cracking criterion, a high strength $7 x x x$ aluminum alloy, which is highly prone to both hot and cold cracking, was selected. The material was cast in the form of a 260-mm diameter billet at Corus-Netherlands (IJmuiden) through DC casting with a conventional mold (without hot top) from the melt that was degassed in the furnace. Constitutive param- 

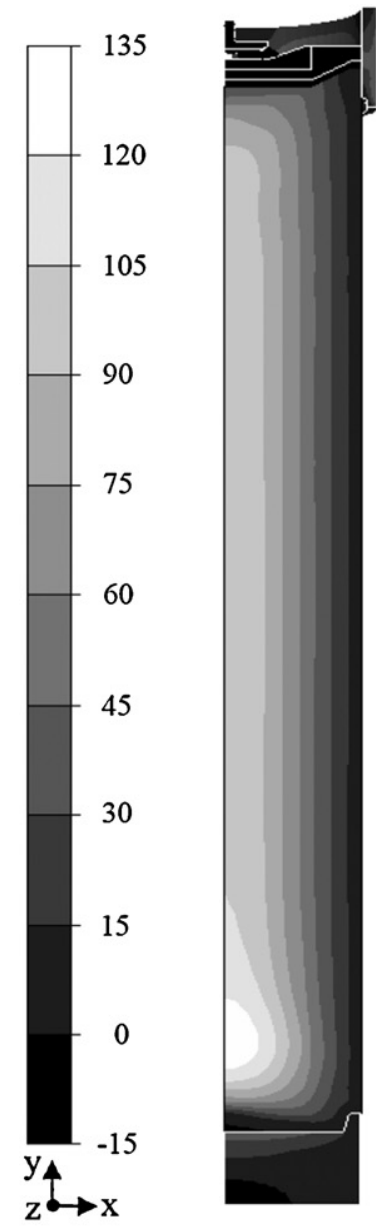

(a) $1 \mathrm{~mm} / \mathrm{s}, 35 \mathrm{l} / \mathrm{min}$

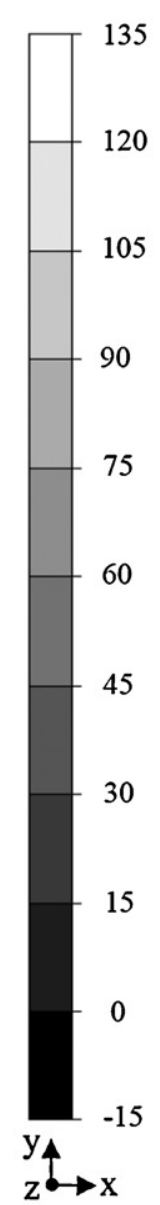

(b) $1.3 \mathrm{~mm} / \mathrm{s}, 351 / \mathrm{min}$

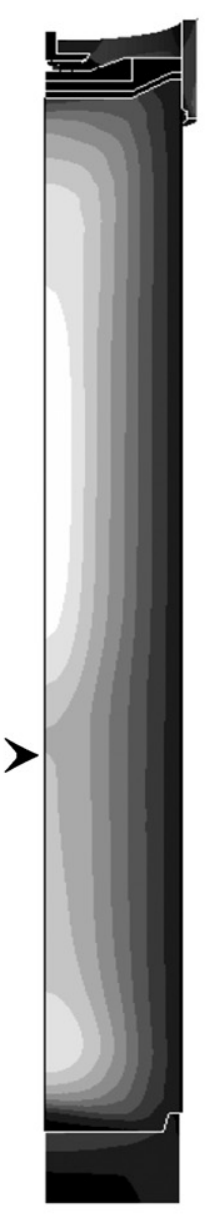

\begin{abstract}
.
\end{abstract}
(c)

(c) $1.8 \mathrm{~mm} / \mathrm{s}, 90 \mathrm{l} / \mathrm{min}$

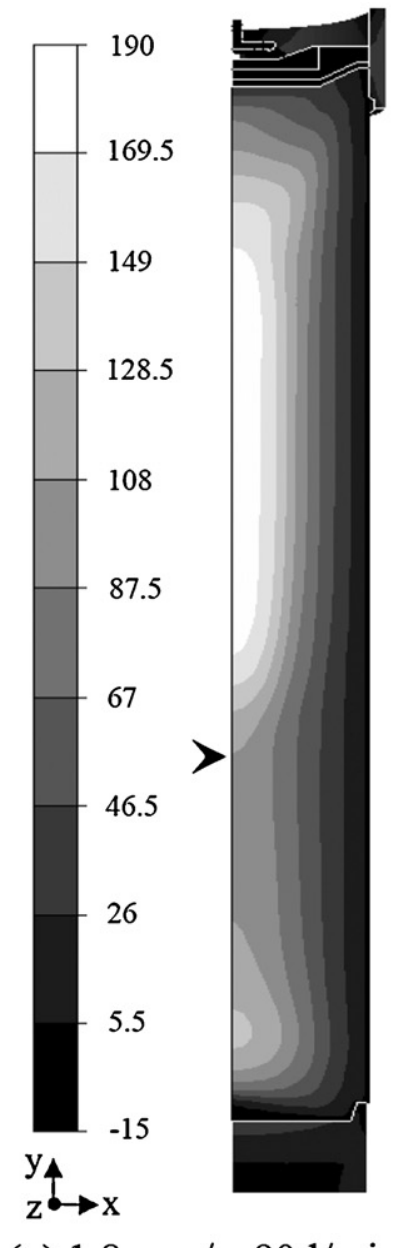

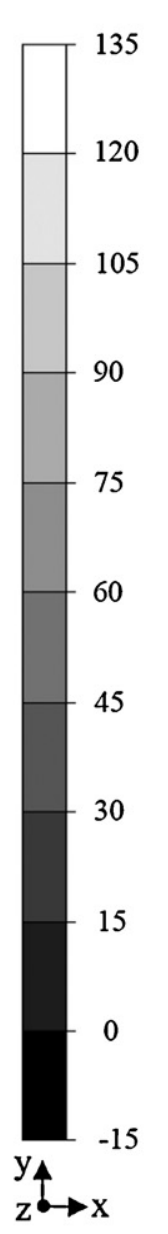

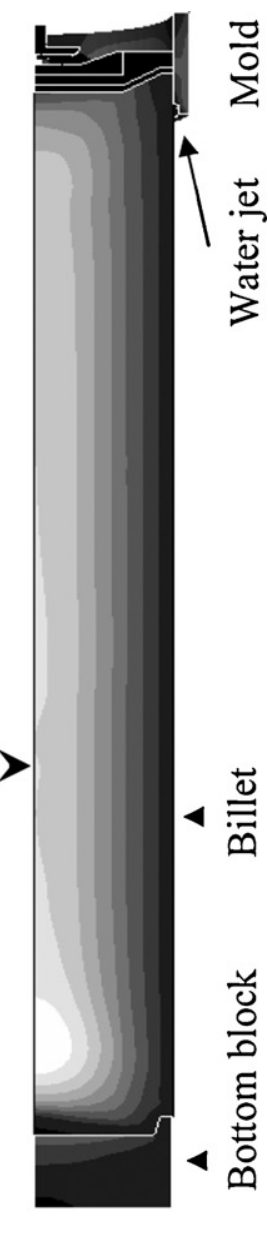

(d) $1 \mathrm{~mm} / \mathrm{s}, 701 / \mathrm{min}$

Fig. 7. Simulation results showing the $\sigma_{11}(\mathrm{MPa})$ in the billets cast at various conditions mentioned in Table 6 . Arrows show the transition between casting regimes [44].

eters and mechanical properties of the alloy were determined by fitting the extended Ludwik's equation [30] to the true stress-strain curves [29]. The plane strain fracture toughness of the material was also determined following the regulations of ASTM-E399 [43]. The mechanical properties of this alloy resemble that of AA7050 [29] except for the fact that the new alloy exhibits more plasticity at $200^{\circ} \mathrm{C}$ and the $K_{\mathrm{Ic}}$ values are higher compared to AA7050. The thermophysical properties of the material were obtained from the JMat-Pro data-base provided by Corus-Netherlands. Finally, mechanical as well as physical properties data-bases were prepared to be implemented in ALSIM5 for thermomechanical simulations and calculation of critical crack sizes.

In order to check the validity of the simulation results, DC-casting trials were performed on billets with two different diameters. $260-\mathrm{mm}$ diameter billets were cast under the conditions mentioned in Table 6 to examine the effect of casting speed and water flow rate. The effect of casting speed on the cracking propensity of the billets was additionally examined on 315-mm diameter

\section{Table 6}

Description of casting process parameters for the $\emptyset 260-\mathrm{mm}$ billets of a $7 x x x$ alloy [44].

\begin{tabular}{lll}
\hline Case & Casting speed $(\mathrm{mm} / \mathrm{min})$ & Water flow rate $(1 / \mathrm{min})$ \\
\hline I & $60(1 \mathrm{~mm} / \mathrm{s})$ & 35 \\
II & $80(1.3 \mathrm{~mm} / \mathrm{s})$ & 35 \\
III & $110(1.8 \mathrm{~mm} / \mathrm{s})$ & 90 \\
IV & $60(1 \mathrm{~mm} / \mathrm{s})$ & 70 \\
\hline
\end{tabular}

billets. DC-casting of two billets (Ø $315-\mathrm{mm}$ ) was simulated and experimentally checked under the following conditions: 1 - casting speed: $50 \mathrm{~mm} / \mathrm{min}(0.8 \mathrm{~mm} / \mathrm{s})$, water flow rate: $42 \mathrm{l} / \mathrm{min}$; 2 - casting speed: $90 \mathrm{~mm} / \mathrm{min}(1.5 \mathrm{~mm} / \mathrm{s})$, water flow rate: $108 \mathrm{l} / \mathrm{min}$. The casting speeds are lowered and the water flow rates are increased correspondingly compared to the $260-\mathrm{mm}$ billet in order to compensate for the larger heat input generated by the larger size of the billet.

Ultrasonic defectoscopy (with accuracy to measure voids as small as $1.5 \mathrm{~mm}$ ) was performed for the non-cracked billets ( $\varnothing 260$ $\mathrm{mm}$ ) to check the presence of voids of critical size which did not lead to catastrophic failure. For more detailed examinations, samples were randomly cut from the center, mid-radius and surface of the billets. They were polished afterwards and prepared for analysis in a Jeol JSM-6500F field emission scanning electron microscope (SEM).

\subsection{Computer simulation results and discussion}

A $260-\mathrm{mm}$ diameter billet, cast at $1 \mathrm{~mm} / \mathrm{s}$ with water flow rate of $35 \mathrm{l} / \mathrm{min}$ was taken as the standard case. Casting speed and water flow rate were varied to study the effect of these variables on the cracking propensity (Table 6) [44]. As in practice, cold cracking frequently occurs at the end of casting when the billet is completely solid, it is decided to adjust the simulation conditions in such a way that they resemble the ones during the failure of the billets in practical situations. To achieve this, the casting conditions were set as 


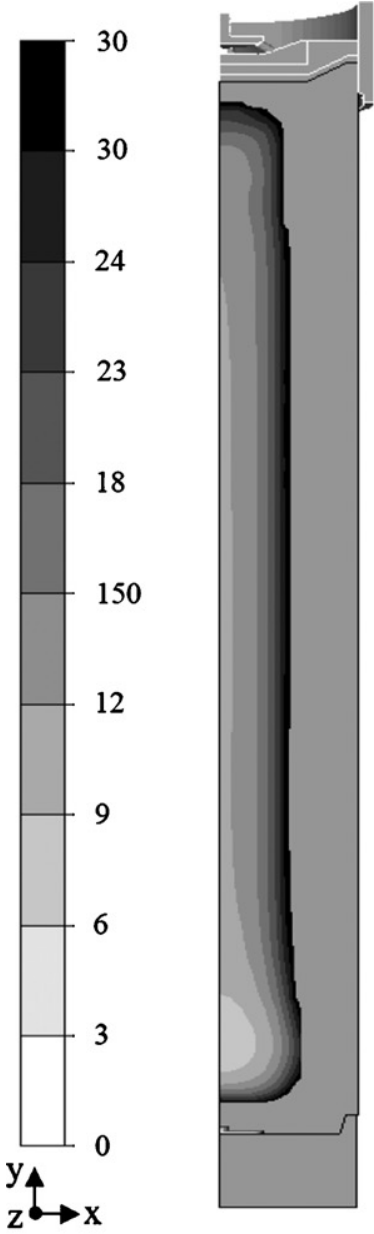

(a) $1 \mathrm{~mm} / \mathrm{s}, 351 / \mathrm{min}$

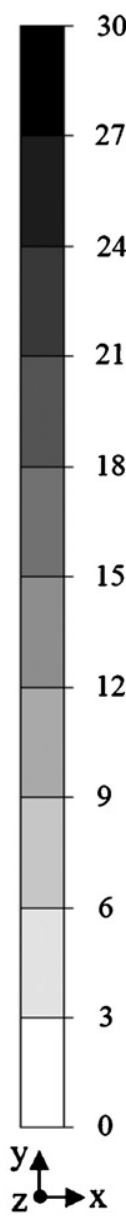

(b) $1.3 \mathrm{~mm} / \mathrm{s}, 35 \mathrm{l} / \mathrm{min}$

18

15

12

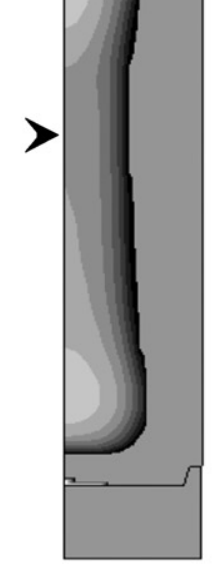

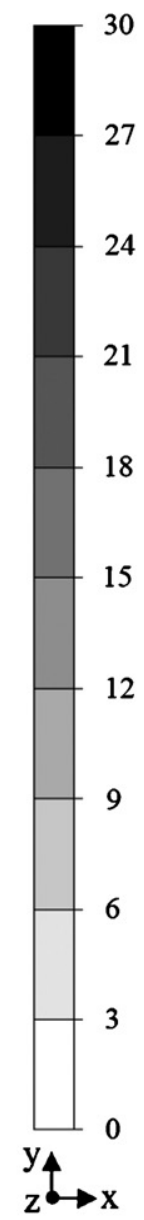

so

27

21

(c) $1.8 \mathrm{~mm} / \mathrm{s}, 90 \mathrm{l} / \mathrm{min}$

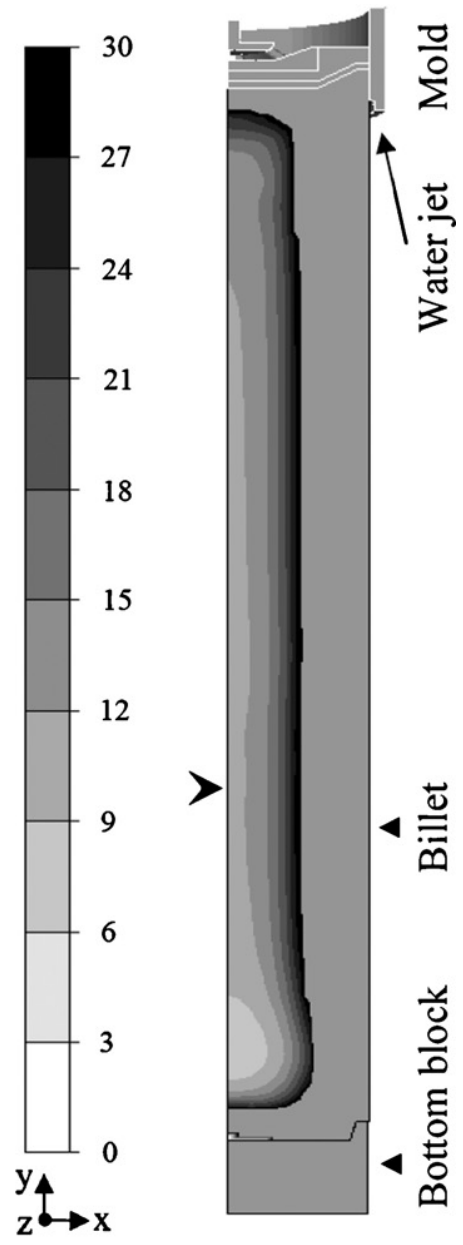

(d) $1 \mathrm{~mm} / \mathrm{s}, 701 / \mathrm{min}$

Fig. 8. Simulation results showing the critical crack size distribution ( $\mathrm{mm}$ ) in the billets cast at various conditions mentioned in Table 6 . Crack sizes larger than $30 \mathrm{~mm}$ are neglected and appear as gray between the billet surface and the black area at mid-radius. Arrows show the transition between casting regimes and the star in (c) indicates the location of the inclusion which triggered the catastrophic failure [44].

follows: 1 - the first 500 s were simulated under standard conditions (Case I in Table 6), 2 - changes in casting speed or water flow rate were applied afterwards by ramping up from Case I, 3 - the casting was then simulated with the new parameters (Cases II, III and IV in Table 6) or the same (Case I) for another $500 \mathrm{~s}, 4$ - eventually, the casting speed was ramped down to zero and the billet was cooled down to room temperature during $200 \mathrm{~s}$.

Contour maps of the $\sigma_{11}$ are shown in Fig. 7 for the cases described in Table 6. In Figs. 7b-d, the lower parts of the billets correspond to the initial casting conditions while the upper parts to the new ones. With increasing the casting speed, the $\sigma_{11}$ increases in the center of the billet (Figs. 7a through c). The increase in the magnitude of the $\sigma_{11}$ is due to the increased heat input and the consequent steeper temperature gradients especially in the axial direction of the billet [17]. Water flow rate has a negligible effect on the magnitude of the $\sigma_{11}$ and the simulation results of the billet cast with $701 / \mathrm{min}$ water flow rate (Fig. $7 d$ ) are very similar to Fig. 7a.

Fig. 8 shows the contour maps of the CCS distribution in billets cast under conditions described in Table 6 . As expected, increasing the casting speed leads to smaller CCS values in the center of the billet, which means higher failure probability (Fig. 8a through c). In agreement with our results in Fig. 7d, the water flow rate has a negligible effect on the crack size (Fig. 8d).
The simulation results of the $\varnothing 315-\mathrm{mm}$ billets were in agreement with our previous findings for AA7050 (Fig. 6), i.e. increasing the billet diameter results in higher stress level in the center of the billet (Fig. 9).

\subsection{Experimental results and discussion}

DC-casting trials performed for the cases mentioned in Table 6 revealed no cracks in cases I, II and IV. A real cold crack however occurred in case III during the casting with an audible bang resulting in the failure of the billet. According to Fig. 8, in the center of the billet, cracks or defects with a critical diameter between 6 and $12 \mathrm{~mm}$ (3-6 mm in radius) may lead to catastrophic failure. Further investigation of the fracture surface in case III revealed an inclusion with a length of $7 \mathrm{~mm}$, which was located $20 \mathrm{~mm}$ away from the center of the billet and $730 \mathrm{~mm}$ above the bottom block (Fig. 10). The predicted critical crack size (the diameter of the penny) for the coordinate mentioned above is $7.5 \mathrm{~mm}$, which is $0.5 \mathrm{~mm}$ longer than the actual observed void. The reason for such a deviation might be the fact that the actual crack shape is more complicated and irregular than the simplified penny shaped crack. In reality, cracks have sharper edges that may approach that of an ideally sharp crack. Under such conditions less energy would be required for the brittle fracture of the material to occur and the failure may occur at 


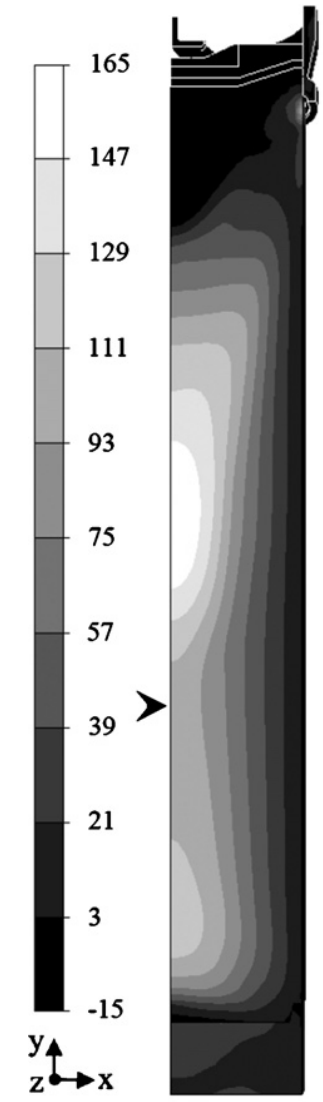

(a) $\sigma_{11}(\mathrm{MPa})$

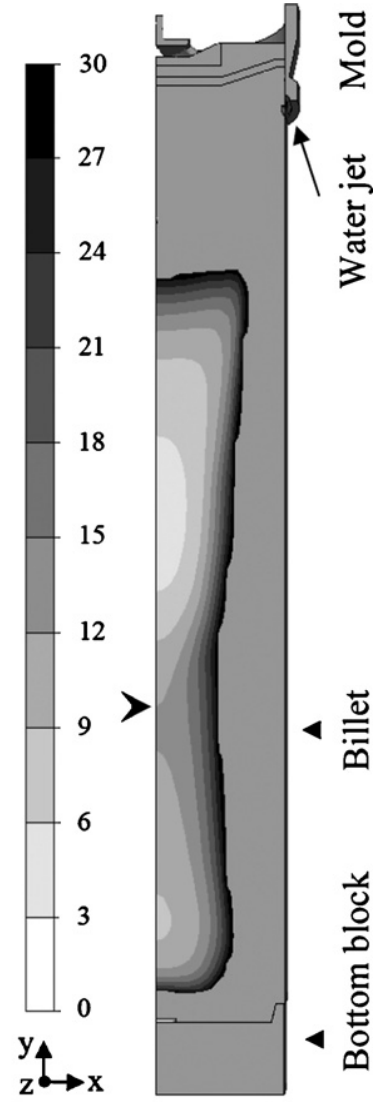

(b) $\operatorname{CCS}(\mathrm{mm})$
Fig. 9. Simulation results showing: (a) the maximum principal stress (MPa) and (b) the critical crack size distribution $(\mathrm{mm})$ in the $315-\mathrm{mm}$ diameter billet cast at $1.5 \mathrm{~mm} / \mathrm{s}$ and $108 \mathrm{l} / \mathrm{min}$ after $980 \mathrm{~s}$ of casting under steady state conditions. Crack sizes larger than $30 \mathrm{~mm}$ are neglected and appear as gray between the billet surface and the black area at mid-radius. Arrows show the transition between casting regimes $(0.8 \mathrm{~mm} / \mathrm{s}, 42 \mathrm{l} / \mathrm{min}$ to $1.5 \mathrm{~mm} / \mathrm{s}, 108 \mathrm{l} / \mathrm{min})$.

lower CCS values. In practice, this may be taken into account by multiplication of the CCS results by a safety factor.

It is obvious from Fig. 10 that the $7 \mathrm{~mm}$ inclusion has triggered the failure as the so-called V-shaped chevron markings are all radiating from this defect. Computer simulation results showed that the temperature of the corresponding point is around $55^{\circ} \mathrm{C}$ at the moment of fracture, which fits in the temperature range where the material is expected to be extremely brittle. Thus, the void existed there since the beginning of the casting, but its catastrophic prop- agation was facilitated by the extreme brittleness of the material below $200^{\circ} \mathrm{C}$ and the high corresponding $\sigma_{11}$ value. Another feature of the crack is that its plane is not oriented parallel to the axial direction of the billet (" $y$ "). As discussed in Section 3, investigation of the stress tensors revealed that the $\sigma_{11}$ axis turns from radial or circumferential direction towards the axial direction $(y)$ of the billet with increasing the casting speed. At the high casting speed of $110 \mathrm{~mm} / \mathrm{min}(1.8 \mathrm{~mm} / \mathrm{s})$, the $\sigma_{11}$ (in the center) turns towards the axial direction of the billet and results in the crack plane oriented normal to " $y$ ". As can be seen in Fig. 11, the normal to the crack plane makes an angle $\theta$ with the axial direction of the billet (direction of casting). In the center of the billet, the crack plane is normal to " $y$ " (Fig. 10). But, as the crack propagates towards the surface of the billet it deviates and tends to orient parallel to the axial direction of the billet. This is mainly due to the rotation of the $\sigma_{11}$-axis with moving towards the surface of the billet.

During the ultrasonic defectoscopy of the non-cracked Ø 260$\mathrm{mm}$ billets no specific defects were detected, in spite of this, two suspicious locations were marked. After stress relief, the billets were cut at those locations and the cross sectional areas were polished; however, no cracks were detected. Closer observations of the samples from the center and mid-radius revealed that there are some voids such as shrinkage porosities in the microstructure with a maximum size in the order of hundred microns (Figs. 12 and 13). At the surface of the billet, no specific voids were detected. The maximum size of the detected shrinkage porosities is far below the estimated critical crack size by fracture mechanics, which explains well why they have not led to the failure of the billets.

DC-casting trials for the $\emptyset 315-\mathrm{mm}$ billets appeared to be more challenging, in spite of this a cold cracking occurred only when the casting speed was raised from 0.8 to $1.5 \mathrm{~mm} / \mathrm{s}$. The billet cast at $1.5 \mathrm{~mm} / \mathrm{s}$ and $108 \mathrm{l} / \mathrm{min}$ cracked with a loud audible bang $15 \mathrm{~s}$ after the end of casting in the pit. At the first glance, the cracks seemed to be originated from the surface of the billet. However, cutting the billets revealed that the cracks initiated in the center of the billet and then propagated catastrophically towards the surface (Fig. 14a and, b). Although it is hard to associate an exact size with the shrinkage cavity in Fig. 14a, its length appears to be $10.5 \mathrm{~mm}$ horizontally and $9.5 \mathrm{~mm}$ vertically. Our simulation results (Fig. 9) showed that for the $315-\mathrm{mm}$ billet cast at $1.5 \mathrm{~mm} / \mathrm{s}$ and $108 \mathrm{l} / \mathrm{min}$, the critical crack size in the center of the billet is $6-12 \mathrm{~mm}$ for the penny shaped crack (the diameter of the penny corresponding to 3-6 mm radius). The size of the shrinkage cavity in the center of the billet matches well to the computed range.

The shrinkage cavities shown in Figs. 12 and 13 are potentially the crack nucleation sites, which may lead to the catastrophic failure if they reach the critical size (Fig. 14a). As explained in Section 1 , the combination of poor thermal properties facilitate the formation various defects during the solidification. This indicates that the
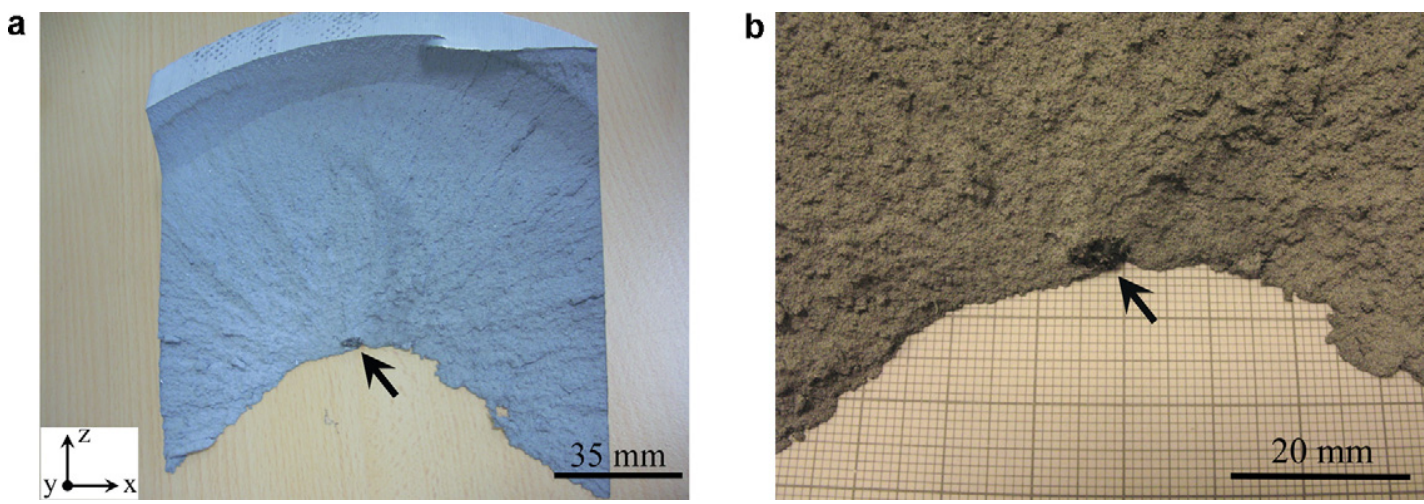

Fig. 10. (a) The cold crack surface in the billet cast at $1.8 \mathrm{~mm} / \mathrm{s}$ and water flow rate of $90 \mathrm{l} / \mathrm{min}$. The dark point shown by an arrow triggered the fracture. The chevron markings radiating from this Mg-oxide inclusion account for its role in the fracture. (b) The same figure at a higher magnification [44]. 


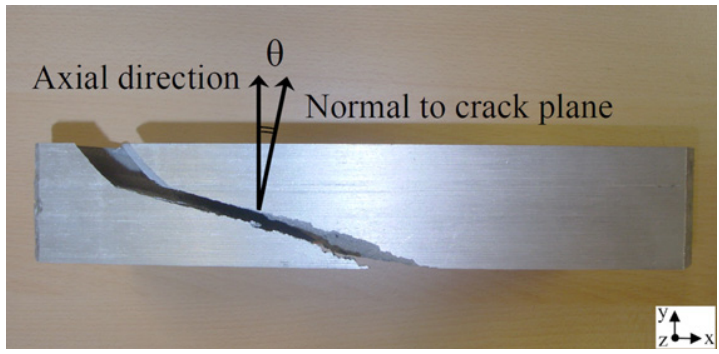

Fig. 11. The lateral cross section of the cracked billet shown in Fig. 10 (the left piece is the same as in Fig. 10). The orientation of the crack plane is shown using the axial direction of the billet and a normal to the plane.
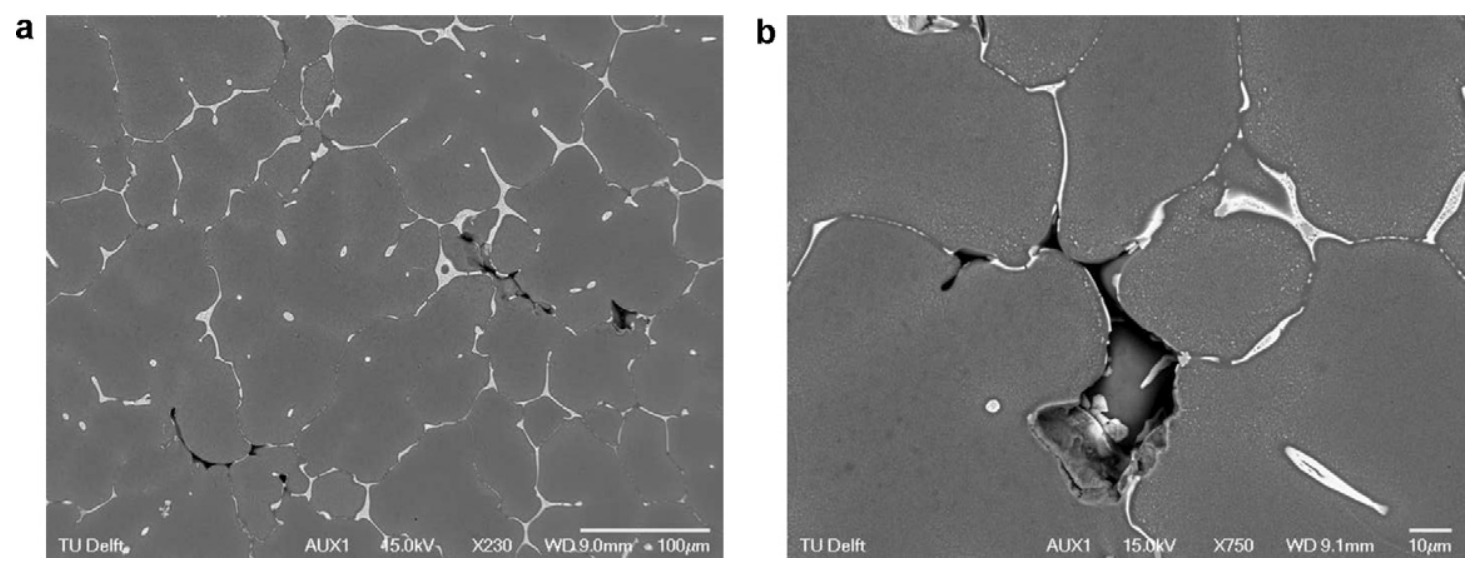

Fig. 12. Electron backscattered images showing various voids formed during the solidification in the mid-radius of a Ø $260 \mathrm{~mm}$ billet of a $7 x x x$ alloy.

$\mathbf{a}$

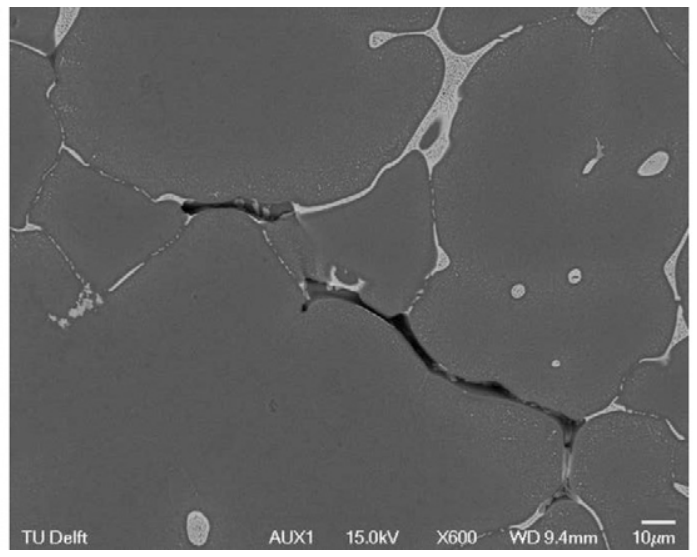

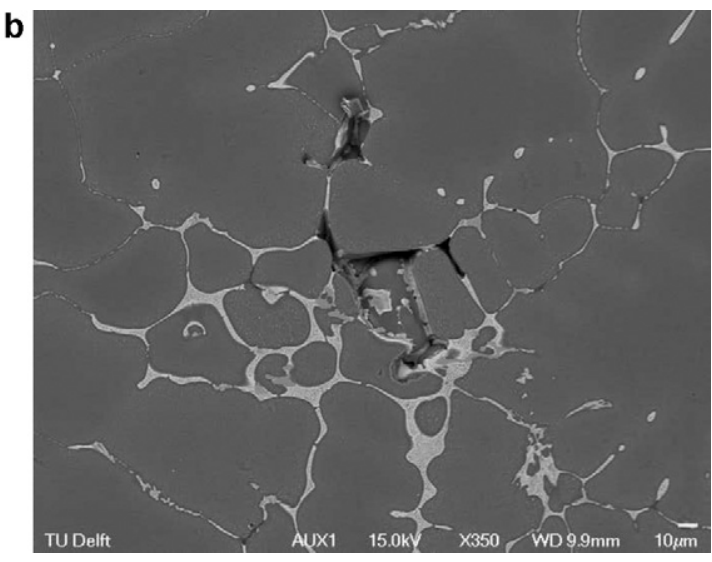

Fig. 13. Electron backscattered images showing various voids formed during the solidification in the center of a Ø $260 \mathrm{~mm}$ billet of a $7 x x x$ alloy.
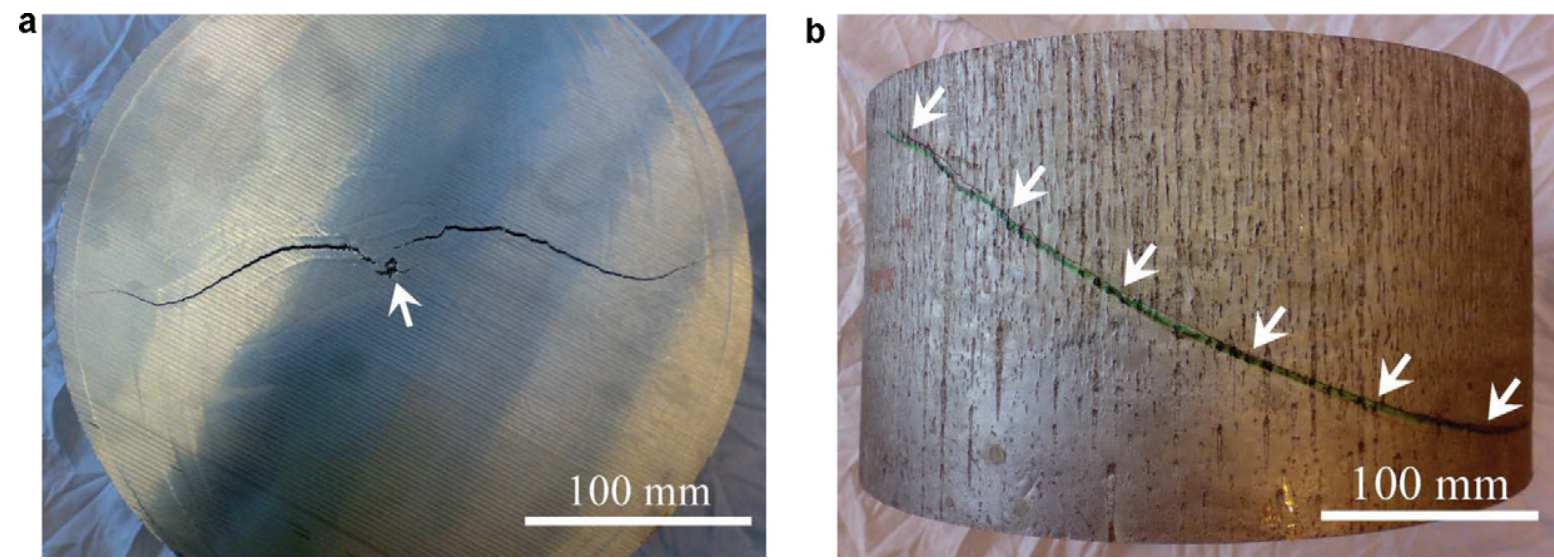

Fig. 14. Photos showing the cracks in the cold-cracked $\emptyset 315-\mathrm{mm}$ billet cast at $1.5 \mathrm{~mm} / \mathrm{s}$ and $108 \mathrm{l} / \mathrm{min}$ : (a) the cross section of the billet; the arrow shows a shrinkage cavity that acted as crack initiator, (b) the outer surface of the billet that shows how the crack plane has propagated towards the surface. 
$7 x x x$ series aluminum alloys are potentially prone to cold cracking. The occurrence of cold cracking however depends on the conditions that may drive such voids to the critical size. Increased casting speed or billet diameter may fulfill such conditions by steepening the temperature gradients and consequently increasing the thermal stress level in the billets. Under such conditions the voids may grow in the tensile stress fields and reach the critical size required for the catastrophic failure.

The effect of the rotation of the $\sigma_{11}$-axis on the orientation of the crack plane at higher casting speeds was shown in Fig. 11 for the $\emptyset 260-\mathrm{mm}$ billet. Similar effect was observed in the $\emptyset 315-\mathrm{mm}$ billet cast at $1.5 \mathrm{~mm} / \mathrm{s}$ (Fig. 14b). With the rotation of the $\sigma_{11}$-axis towards the axial direction of the billet $(y)$, the crack plane propagates in such a way to orient perpendicular to that component. Another point to bear in mind is that the $\varnothing 315-\mathrm{mm}$ billet cracks at a lower casting speed $(1.5 \mathrm{~mm} / \mathrm{s})$ compared to the $260-\mathrm{mm}$ billet $(1.8 \mathrm{~mm} / \mathrm{s})$. This is the result of the stress level rise in the billet through increased billet diameter.

\section{Concluding remarks}

The cold cracking propensity of AA7050 billets was studied under steady state conditions during DC-casting. The contour maps of the critical crack size calculated by ALSIM5 for the penny shaped crack admitted our earlier findings [17] that the center and the water impingement zone are the most vulnerable locations of the billet to cracking. The effects of the casting speed and billet diameter were also studied. The results revealed that at higher casting speeds or larger billet diameters the vulnerable area to cold cracking becomes larger in the center while it becomes smaller at the surface in the water impingement zone. The larger heat input brought about by the faster casting speeds or larger billet diameters results in steeper temperature gradients especially in the axial direction of the billet. The direct consequence of the increased temperature gradients is the elevation of the stress level in the center as well as the surface of the billets in the WIZ, which causes higher cracking probability in these locations.

The cold cracking criterion was validated quantitatively upon DC-casting of a $7 x x x$ series aluminum alloy, which is highly prone to both hot and cold cracking. Thermomechanical simulations were run for this alloy under various casting conditions. In agreement with our earlier findings [17], the simulation results showed that as the casting speed increases, the CCS decreases leading to a higher failure probability of the billets. Computer simulations were followed by experimental DC-casting trials to check the critical crack sizes calculated by ALSIM5. The critical crack sizes were validated upon experiments, where a $7 \mathrm{~mm}$ inclusion in the center of the $\varnothing$ $260-\mathrm{mm}$ billet cast at $110 \mathrm{~mm} / \mathrm{min}(1.8 \mathrm{~mm} / \mathrm{s})$ and $90 \mathrm{l} / \mathrm{min}$ triggered the catastrophic failure. The model was further validated by casting a billet of a larger diameter, where a shrinkage cavity of critical size triggered cold cracking.

Our microstructural investigations on non-cracked billets showed that the shrinkage cavities formed during the solidification are the potential nucleation sites for cold cracking. However, they may only reach the critical size under severe casting conditions provided by the higher casting speeds or larger billet diameters. Other defects such as hot cracks or inclusions may also reach a critical size and trigger the failure. Therefore, the intrinsic propensity of $7 x x x$ series aluminum alloys to cold cracking thorough their poor thermal properties and low ductility may actually lead to cold cracking when the externally controlled process parameters exceed some critical levels, or when an external void of critical size (inclusion) is added to the system during the casting.

Based on our earlier findings [17], increasing the casting speed not only increases the magnitude of the maximum principal stress, but it also turns its axis towards the axial direction of the billet resulting in the rotation of the crack plane. The orientation of the crack plane in the cold-cracked billet with respect to the axial direction of the billet proves this simulation result.

\section{Acknowledgments}

This research was carried out under the project numbers MC4.05237 and MA.09147 in the framework of the Research Program of the Materials innovation institute (www.m2i.nl). Support and fruitful discussions with Dr. W. Boender (Corus R\&D) are appreciated. Another important basis of the present paper is given by comments received from $\mathrm{Mr} \mathrm{D}$. Mortensen. Remarks offered by Dr. M. Janssen in interpreting the failure mechanisms are also appreciated.

\section{References}

[1] E.F. Emley, Int. Met. Rev. 21 (1976) 75-115.

[2] N.A. Belov, D.G. Eskin, A.A. Aksenov, Multicomponent Phase Diagrams: Applications for Commercial Aluminum Alloys, Elsevier Ltd., Amsterdam, 2005.

[3] F. Xie, X. Yan, L. Ding, F. Zhang, S. Chen, M.G. Chu, Y.A. Chang, Mater. Sci. Eng. A 355 (2003) 144-153.

[4] D.G. Eskin, L. Katgerman, Metall. Mater. Trans. A 38 (2007) 1511-1519.

[5] J.B. Hess, Metall. Trans. A 14 (1983) 323-327.

[6] M. Lalpoor, D.G. Eskin, G. ten Brink, L. Katgerman, Mater. Sci. Eng. A 527 (2010) 1828-1834.

[7] Z. Yubo, C. Jianzhong, Z. Zhihao, Z. Haitao, Q. Ke, Mater. Sci. Eng. A 406 (2005) 286-292.

[8] M. Lalpoor, D.G. Eskin, L. Katgerman, Metall. Mater. Trans. A 40 (2009) 3304-3313.

[9] O. Ludwig, J.-M. Drezet, B. Commet, B. Heinrich, in: C.-A. Gandin, M. Bellet (Eds.), Modeling of Casting, Welding and Advanced Solidification Processes-XI, TMS, Warrendale, PA, 2006, pp. 185-192.

[10] W. Boender, A. Burghardt, in: H. Jones (Ed.), Proceedings of the 5th Decennial International Conference on Solidification Processing, University of Sheffield, Sheffield, United Kingdom, 2007, pp. 714-718.

[11] B. Hannart, F. Cialti, R.v. Schalkwijk, in: U. Mannweiler (Ed.), Light Metals, TMS, San Francisco, CA, USA, 1994, pp. 879-887.

[12] J.H. Faupel, F.E. Fisher, Engineering Design, John Wiley \& Sons, Inc., New York, NY, USA, 1981.

[13] W. Boender, A. Burghardt, E.P.v. Klaveren, J. Rabenberg, in: A.T. Tabereaux (Ed.), Light Metals, TMS, Warrendale, PA, 2004, pp. 679-684.

[14] R.K. Paramatmuni, K.-M. Chang, B.S. Kang, X. Liu, Mater. Sci. Eng. A 379 (2004) 293-301.

[15] J.R. Davis, ASM Specialty Handbook: Aluminium and Aluminium Alloys, ASM International, Materials Park, OH, 1993.

[16] M. Lalpoor, D. Eskin, L. Katgerman, Adv. Mater. Res. 89-91 (2010) 319-324.

[17] M. Lalpoor, D.G. Eskin, L. Katgerman, Metall. Mater. Trans. A 41 (2010) 2425-2434

[18] W. Roth, Z. Metallkd 40 (1949) 445-460.

[19] V.A. Livanov, in: A.F. Belov, G.D. Agarkov (Eds.), Aluminum Alloys, Oborongiz, Moscow, 1955, pp. 128-168.

[20] J.L. Dassel, T.C. Zinniger (Eds.), Light Metals, TMS, Warrendale, PA, 1982, pp. 793-801.

[21] R.B. Wagstaff, W.J. Fenton, Homogenization and heat-treatment of cast metals, US Patent 2007/0102136 A1, USA, 2007.

[22] I.L. Teitel, Wrought Aluminum Alloys, Oborongiz, Moscow, 1961.

[23] E.E. Madsen, G.E. Fladmark, in: G.E. Fladmark, J.G. Gram (Eds.), Numerical Solution of Partial Differential Equations, D. Reidel Publishing Company, Kjeller, Norway, 1973, pp. 223-240.

[24] E.E. Madsen, in: R.W. Lewis, K. Morgan (Eds.), Numerical Methods in Thermal Problems, Pineridge Press Limited, 1979, pp. 81-89.

[25] H. Fossheim, E.E. Madsen, in: W.S. Peterson (Ed.), Light Metals, TMS-AIME, Warrendale, PA, 1979, pp. 695-720.

[26] E.K. Jensen, W. Schneider, in: C.M. Bickert (Ed.), Light Metals, TMS-AIME, Warrendale, PA, 1990, pp. 937-943.

[27] H.G. Fjær, A. Mo, Metall. Trans. B 21 (1990) 1049-1061.

[28] D. Mortensen, Metall. Mater. Trans. B 30 (1999) 119-133.

[29] M. Lalpoor, D.G. Eskin, L. Katgerman, Proceedings of the 12th International Conference on Fracture, National Research Council of Canada (CD), Ottawa, Canada, 2009.

[30] B. Magnin, L. Katgerman, B. Hannart, in: M. Cross, J. Campbell (Eds.), Modelling of Casting, Welding and Advanced Solidification Processes VII, TMS, Warrendale, PA, 1995, pp. 303-310.

[31] O. Ludwig, B. Commet, J.-M. Drezet, C.L. Martin, M. Suery, in: D.M. Stefanescu, J. Warren, M. Jolly, M. Krane (Eds.), Modeling of Casting, Welding and Advanced Solidification Processes X, TMS, Warrendale, PA, 2003, pp. 183-190.

[32] M. M'Hamdi, A. Mo, H.G. Fjær, Metall. Mater. Trans. A 37 (2006) 3069-3083. 
[33] D.G. Eskin, J.F. Suyitno, L. Mooney, Katgerman, Metall. Mater. Trans. A 35 (2004) 1325-1335.

[34] O. Ludwig, J.-M. Drezet, C.L. Martin, M. Suery, Metall. Mater. Trans. A 36 (2005) 1525-1535.

[35] M. Schöllmann, H.A. Richard, G. Kullmer, M. Fulland, Int. J. Fracture 117 (2002) 129-141.

[36] H. Tada, P.C. Paris, G.R. Irwin, The Stress Analysis of Cracks Handbook, ASME Press, New York, NY, 2000.

[37] G.E. Dieter, Mechanical Metallurgy, McGraw-Hill Book Co., Singapore, 1988.

[38] C.S. Wu, J. Mater. Sci. 23 (1988) 606-610.
[39] Q Han, S. Viswanathan, D.L. Spainhower, S.K. Das, Metall Mater. Trans. A 32 (2001) 2908-2910

[40] S. Benum, D. Mortensen, H. Fjær, H.-G. Øverlie, O. Reiso, in: W. Schneider (Ed.) Light Metals, TMS, Warrendale, PA, 2002, pp. 967-974.

[41] D.G. Suyitno, L. Eskin, Katgerman, Mater. Sci. Eng. A 420 (2006) 1-7.

[42] J.F. Grandfield, P.T. McGlade, Mater. Forum 20 (1996) 29-51.

[43] ASTM, ASTM Standards on Disc, vol. 03.01, ASTM, West Conshohocken, Philadelphia, 2003.

44] M. Lalpoor, D.G. Eskin, H.G. Fjær, A. Ten Cate, N. Ontijt, L. Katgerman, Mater. Sci. Forum 654-656 (2010) 1432-1435. 